\title{
A Corpus-Based Comparative Study of Derivational Morphemes Across ENL, ESL, EFL Learners Through ICNALE
}

Correspondence: $\quad \begin{aligned} & \begin{array}{l}\text { Muhammad Farukh Arslan } \\ \text { <Farukhgil199@gmail.com> }\end{array} \\ & \begin{array}{l}\text { Prof. Dr. Muhammad Asim Mahmood } \\ \text { <masimmahmood@gcuf.edu.pk> }\end{array} \\ & \begin{array}{l}\text { Attia Rasool } \\ \text { <attia.rasool@yahoo.com> }\end{array}\end{aligned}$

PhD Scholar, Department of Applied Linguistics, Government College University, Faisalabad, Pakistan.

Dean, Faculty of Arts and Social Sciences, Government College University, Faisalabad, Pakistan.

PhD Scholar, Department of Applied Linguistics, Government College University, Faisalabad, Pakistan.

\begin{abstract}
This corpus-based comparative study was about morphemic derivational patterns in grammatical categories: adjective, noun and verbs in different varieties: English as native language (ENL), English as second language (ESL), and English as foreign language (EFL). This study was done on data collected from ICNALE in which learners' data from three different varieties of English was compared. The data was tagged through CLAWS tagger and analyzed through AntConc software. In result of analysis, the frequency-based differences in the morphemic derivational patterns were observed after normalizing the data. Such differences across varieties in morphemic patterns were realized through the existence and absence of derivational morphemes. The results showed that the native speakers have higher ability of using a greater number of morphemic patterns than second and foreign language speakers of English. Due to their native like competence, they are more competent is the usage of morphemic derivational patterns. Those distinctive patterns should also be taken as pedagogical implication for second and foreign language learners of English. It can also be helpful for second and foreign language learners in achieving native like ability to use English language.
\end{abstract}

Keywords: Morphemes, Derivational, Inflectional morphemes, Morphemic pattern, ICNALE

\section{Introduction}

This is a comparative study about the patterns, variations in the use, and frequency of derivational morphemes across three varieties of English: ENL, ESL and EFL. The data from these varieties are taken for the study. ENL represents the native data, ESL represents second language users which includes Pakistani portion of ICNALE, and EFL represents foreign language users which constitutes Chinese portion.

Corpus as methodology has been employed in this study. Corpus is termed as machine readable data which can be processed and analyzed though software. Antconc is the software used for the analysis of tagged corpus. Corpus is tagged through CLAWS tagger that is an online Parts of Speech (POS) tagger. The data were taken from ICNALE that is online available for research purpose.

This study basically aims to find out the occurrences and variations of derivational morphemes. The language proficiency varies as the status of the speaker as language user varies. It can be either as native, second or foreign language (Kachru, 1981). In this study, the researcher has analyzed, compared and found the conclusive differences through occurrence of derivation morphemes serving in the formation of words. The differences are reported in the result section.

Jassem (2013) has conducted the study about the relation between derivational morphemes in English, French, Arabic, Latin and German by applying the lexical route theory. Study concluded that all these languages are considered as the part of different language families but study showed that these languages are interrelated and derived from one another which means that all these above-mentioned languages are inter-related have something in common.

\section{Literature Review}

In this section, I intended to construct the base of my particular study. Firstly, I took start by defining the broader field of morphology to construct the base and place my study in the particular branch of linguistics. Then I moved towards the notion of morphemes and differentiated the kinds of morphemes. Then I related the notion of morphemes to the theory of SLA because SLA has a key role in language acquisition and the language acquisition is then related to the notion of morphology. Then I moved towards the approach of corpus which is taken as methodology in this study. Then moved towards particular data which is taken in this study. Lastly, I mentioned the studies conducted in the past regarding this particular notion of morphemes and I compared that methodology with my approach.

\subsection{Morphology}

Morphology is the study of joining derivational and inflectional morphemes to the words base form to perform functions in the syntax. Morphology is the basic stage of language formation. Meaningful units of language in the form of words are formed in morphology. In this connection, morphology is the study of the combination morphemes to yield words (Haspelmath \& Sims, 2013). 
Language is a basic tool of communication and the morphemes are the basic fundamental, and meaningful unit of language. Morphemes are the study of word formation. Boey (1975) stated that the morphemes are the basic unit of language formation. So, in this way either to communicate through a language or understand the communication of a language it is necessary to grasp the process of language formation with the help of morphemes.

\subsection{Morphemes}

The meaningful unit of a phrase is a morpheme (Edward, 2003). There are basically two kinds of morphemes: free and bound morphemes. Free morphemes can stand alone but bound morphemes need to be attached with free morphemes to make meaning. Bound morphemes are further divided in two categories: derivational and inflectional morphemes.

Bound morphemes cannot stand alone at their own and those bound morphemes do not convey any meaning until they are attached with the root of the word. According to my understanding bound morphemes are not meaningful until they are attached with any root of the word.

Inflectional morphemes are -s (or -es); 's (or s'); -ed; -en; -er; -est; and -ing which are joined with free morpheme or base form of words as suffix to make meaningful word. Inflectional morphemes are of limited category and derivational morphemes are more in number. Derivational morphemes can be sometimes joined as prefix (before word) such as un-, dis-, and suffix (after word) -ment, -ish etc. This process of fixing morphemes is called affixation (Yule, 2016).

Now I will move towards the proper concern of this study which is derivational morphemes. Derivational morphemes are actually bound morphemes which are attached to the words and they change the grammatical category of the word such as by adding the derivational morpheme (-ment) to the word accomplish makes the word accomplishment and changes the category from verb to noun. Grammatical category is changed but syntactic form of the lexical item remains the same (Bauer, 1988).

Derivational morphemes help in forming the words of different grammatical and semantic category. Derivational morphemes can be attached at the beginning of the words as prefix and it helps in changing the semantic category and as suffix it helps in forming different grammatical category of the word.

Authentic $>$ Un authentic helps in changing the semantic category

Authentic $>$ Authentica(tion) helps in changing the grammatical category

In some occurrences in the English derivation and inflectional morphemes can occur on same time with the base form of the word.

Bowl (er) derivational morpheme (s) inflectional morpheme

Teach (er) derivational morphemes (s) inflectional morpheme

In this way, we can see that both kinds of morphemic patterns can occur in the single word.

This particular review is about to observe the frequencies of derivational morpheme patterns. This study also intends to observe the occurrence of patterns making nouns by joining the derivational morphemes with the root of word. In the same way, the study intends to observe the patterns deriving the adjectives and verbs by joining the derivational morphemes with the root.

\subsection{SLA and Morphology}

A key concept regarding learning the patterns of morphology is "contrastive hypothesis". This hypothesis states that the first language of the learner effects second language learning. Similarities or the differences in patterns of both languages can support or hinder the process of learning. The effect of L1 continues in both situations.

Contrastive hypothesis states that change in the behavior of target language of the learner and native language leads to the difference in language behavior. Here the role of a linguist begins. The role of the linguist is to identify the differences in the language behavior, then the writer of language teaching material develops the material and make the teachers aware of the differences and helps the leaner to learn more efficiently (Wardhaugh, 1970).

Cook (2008) stated that any language which learners learn in addition to mother tongue is known as second language. Second language learning is an intentional and conscious process. Learner learns second language with the help of institutional support. During second language learning the first language of the learner plays vital role. Dost and Bohloulzadeh (2017) examined the implication of the contrastive hypothesis with relation to the two languages English and Persian regarding the phonological and syntactic features of two languages, in this study similarity and differences between two languages were discussed which would play vital role in second language learning.

First language acquisition and second language learning are two different processes. Bi- or multi-lingual speakers learn additional languages with their first language. Whenever the speakers learn any language in addition to their first language. The impact of first language is obvious on second language.

So, if we relate this contrastive hypothesis to English language, it can be concluded that a speaker having English as first language would have different understanding of English as compared to the speaker for whom English is second or foreign language. Specifically speaking the speakers of English language can be differentiated in three main categories ENL, EFL and ESL.

ENL includes those speakers who have English as their first language. It includes the countries like UK and USA. ESL include those countries those countries who have English as their second language in addition to their first language and use English to communicate with in their country to communicate in addition to their native language. EFL includes the speakers who have English as foreign language. In addition to their native or local language these speakers use English to communicate outside the country.

\subsection{Corpus-Based Study}

Now, I would like to introduce and explain corpus which I took as methodology for this study. After the introduction and explanation of the corpus, I would like to introduce historically and recently developed corpora which proved helpful in linguistic analysis. Then, I will justify the methodology of corpus for linguistic analysis.

My intuition about corpus is that it is a large body of language data which is machine readable and helps the researcher to analyze and extract the results and generalize the results over the population. No doubt, corpus linguistics is a growing field of the $19^{\text {th }}$ century and it has made the language analysis easier, efficient and more objective. 


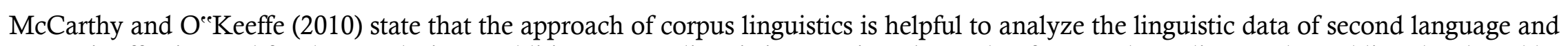
corpus is effective tool for data analysis. In addition, corpus linguistics practices the study of concordance lines and word lists developed by machine software. This approach of explanation the text based on the occurrences of words and phrases in a text helps to explore the linguistic material.

In continuation, the Brown Corpus consisted upon 1,014,300 words, LOB Corpus confined one million words and LLC consisted upon 500,000 words of spoken form of British English. Other types of corpora developed for studying spoken English include which consisted upon 52,600 words of spoken form of standard British English, CSAE consisted upon one million words (Demirela \& Kazazoğlub, 2015).

Now, I would like to move towards the learner corpora which is the main concern of this study. This study took data from learner corpora to analyze the linguistic data. There are many learner corpora developed which are available for the analysis of linguistic content. ICLE is the main and influential learner corpora but its application is inadequate due to the less exposure of Asian languages (Ishikawa, 2011).

\subsection{The International Corpus Network of Asian Learners of English}

This particular study is about the analysis of the data derived from International Corpus Network of Asian Learners of English (ICNALE) which is an international learner corpus composed by Dr. Shin Ishikawa. ICNALE includes 10,000 English writing essays on a specific topic; the speeches by ten native English speakers and Asian countries speakers. ICNALE is present in four written form essays, spoken monologue and dialogue, and edited essays. In this way, ICNALE has become the largest learner corpora and it is publicly available for the research purposes (Ishikawa, 2019).

ICNALE includes the data from all three varieties. Native, second and foreign languages. The said typology was developed and proposed by Kachru (1985) who divided the English language in three circle model: inner, outer and expanding circle.

Inner circle includes speakers who are the native speakers of English language and they are referred as ENS- they are norm provider; they have the basic control and authority over English language. Outer circle consists upon the speakers who have English and second language and they are referred as ESL. ESL speakers are norm developers. While using the language the change which arises due to the influence on native language of the ESL speakers the change which appears in English language is compared with ENS. Expanding circle includes the speakers who have English as foreign language. Finally, it covers all the population of learners belonging to ENL, ESL and EFL background.

Table 1: ICNALE data from different countries

\begin{tabular}{l|l|l}
\hline ENL & ENS & UK, USA, Australia \\
\hline ESL & HKG, SIN, PK, PHL & Hong Kong, Singapore, Pakistan, Philippines \\
\hline EFL & CHN, IDN, JPN, KOR, THI, TAW & China, Indonesia, Japan, Korea, Thailand, Taiwan \\
\hline
\end{tabular}

Source: Ishikawa (2013)

This study is about the frequencies and patterns of derivational morphemes across different patterns of making nouns, verbs and adjectives. In this study, frequency and patterns of deriving noun, verb, and adjectives with the help of derivational morphemes across different varieties of ICNALE data.

Now, I would like to quote the previous studies performed regarding the notion of morphemic patterns. Jassem (2013) implemented Lexical root theory approach to study the morphemic patterns. Lexical root theory has five basic steps. First among these is "methodological", second one is "lexicological", third one is "linguistic", fourth one is "relational", and fifth and last one is "comparative".

Jassem (2013) conducted the study about the relation between derivational morphemes in English, French, Arabic, Latin and German by applying the lexical route theory and concluded that all these languages are stated as the part of different language family but study showed that these languages are interrelated and derived from one another.

This approach can be suit able while comparing and relating two or more languages. The corpus-based approach reduces human subjectiveness. Corpus leads to wide data analysis that is the reason I preferred the approach of corpus of manual and subjective analysis. The approach of corpus creates more authenticity in the study.

I am refereeing to the other approach to study morphemes just to show the comparison between both approaches and I suggest the researchers to adopt and shift towards the approach of corpus to make studies more authentic and less subjective.

After going through such studies, I have been able to propose the followings questions for the current study.

1) What is the frequency of derivational morphemes of grammatical categories: adjective, noun and verbs across ENL, ESL, and EFL?

2) What kind of derivational morphemes are found in grammatical categories: adjective, noun and verbs across ENL, ESL, and EFL?

3) What kind of variations do occur in morphemic patterns?

\section{Methodology}

\subsection{Data collection}

In this section I shall describe the process in detail through which I conducted this study. I shall explain the process of methodology in detail. All steps of methodology comprising upon the steps of data collection and analysis will be explained in this section. As I intended to conduct the study about the derivational morphemes found in English language to derive the words of English language.

This is a corpus-based research. I took the ICNALE data which is online available for research purposes. I took Pakistani, Native and Chinese portion from ICNALE to represent all three categories of English speakers. Native portion represents the data of speakers belonging to ENS, Pakistani portion represents the speakers belonging to ESL and Chinese portion represents the speakers from EFL countries. This division would represent all three categories. Main concern is the Pakistani portion and the remaining two portions are taken to provide the reference point and to conduct the comparison. ICNALE has the data of Asian countries except India and Sri Lanka and further, it includes the native speaker proportion in form of written essays, spoken monologues and dialogues. 


\subsection{Data Analysis}

First, I took the data from ICNALE consisting upon Pakistani, Chinese and native speaker proportion. I took both written and spoken data. After I compiled the files of written and spoken data separately repressing all three varieties of English language. The data was tagged through CLAWS C7. Secondly, the tagged data was analyzed with the help of AntConc and the lists of adjectives, nouns and verbs were extracted.

As the study is about the patterns of derivational morphemes- I analyzed these lists of three grammatical categories and analyzed the patterns of derivational morphemes. Next, I analyzed the data through both approaches qualitatively and quantitatively. Keeping in mind the paradigm of quantitative approach, I extracted the frequencies of derivational morphemes deriving adjectives, nouns, and verbs in both forms (written and spoken) of English language from all three categories.

In qualitative analysis, I intended to extract the patterns which are followed in the development of adjectives, nouns, and verbs with the help of derivational morphemes. Further, the lists of three grammatical categories belonging to three varieties of English language in both written and spoken forms were analyzed to extract the pattern of derivational morphemes added with the root of the word. The patterns were highlighted and their frequencies were calculated for the comparison with other varieties. Frequencies of the patterns were normalized by multiplying with a constant standard figure. I took 100,000 to normalize the frequency. These were extracted and patterns were devised from all the grammatical categories and the varieties of English.

\subsection{Results}

All three research questions are answered in this section. In this section, I will report the frequencies of derivational morphemes making three grammatical categories in three varieties of English language. Further, these frequencies are displayed in the form of graphs individually to describe them in more detail separately. Then, all the derivational morphemes found in the data are presented in the section bellow. In the last section, morphemes across three varieties are compared and the patterns are presented on the basis of existence and absence of the morphemes across three varieties both mediums, and three grammatical categories of English language.

This table represents the overall normalized frequencies of derivational morphemes making adjectives, nouns and verbs. Frequencies of all three varieties of English language are given in the table below.

Table 2: Frequency and distribution in corpus

\begin{tabular}{l|c|c|c}
\hline Varieties & Adjective & Noun & Verb \\
\hline Paki spoken & 3516.25 & 3765.86 & 34.61 \\
\hline Paki written & 2022.78 & 3092.36 & 5.28 \\
\hline Chinese Spoken & 1445.53 & 1728.97 & 5.96 \\
\hline Chinese Written & 999.38 & 1905.01 & 5.42 \\
\hline ENS Spoken & 1438.91 & 2378.72 & 12.73 \\
\hline ENS Written & 1865.07 & 4168.27 & 26.48 \\
\hline
\end{tabular}

Graph 1: Comparison of three grammatical categories of three varieties across written and spoken data

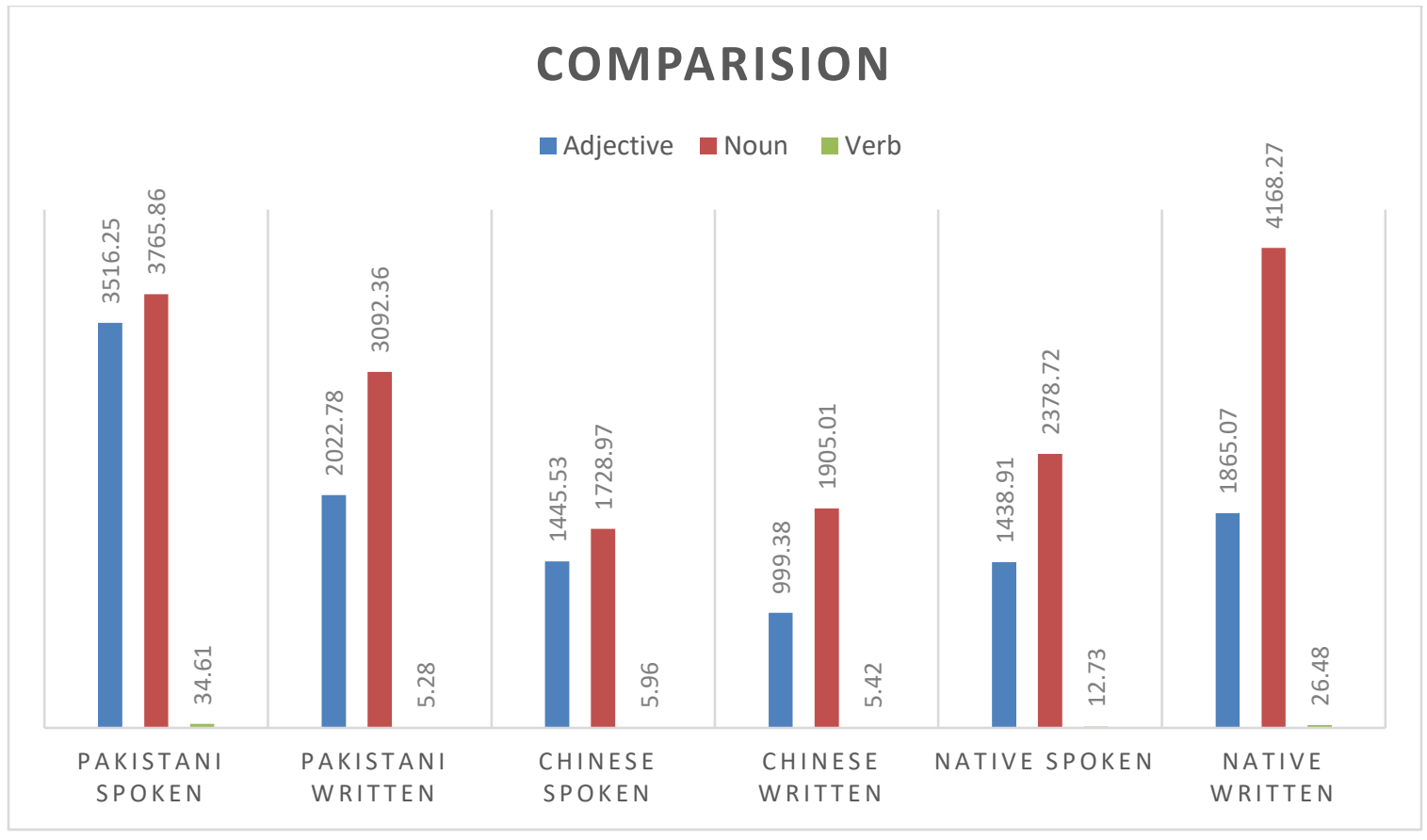

This graph gives the overall comparison of three varieties considering both written and spoken forms. The spoken data of Pakistan showed almost an equal proportion of nouns and adjectives. On the other hand, the spoken data showed that nouns are more frequent than adjectives and the gap between the frequencies of both grammatical categories is greater than the spoken data of Pakistan.

Chinese data form both written and spoken forms showed very low frequency as compared to two other varieties but the spoken data of Chinese showed a proportion between adjectives and nouns as the Pakistani spoken data showed. The frequency of verbs is very low in Chinese data.

Data from the category of spoken native speakers showed that nouns are at higher frequency and adjectives also have quite similar proportion. Frequency of adjectives and nouns in spoken data have same frequency and on the other hand in written form of native data showed nouns in a very high frequency made with the help of derivational morphemes. In fact, the frequency of nouns in native written data is most among all other categories of all varieties. The frequency of verbs is very low as the all-other forms and varieties showed.

In the tables below, I am giving examples of each morphemic pattern through which those morphemes are making the words. These morphemes are found in the text at higher frequency but I am sharing only one example to report the pattern.

Table 3: Pakistani Spoken

\begin{tabular}{l|l|l}
\hline Adjectives & Nouns & Verbs \\
\hline Specific (ic) & Adulthood (hood) & Mimic (ic) \\
\hline Eatable (able) & Justice (ice) & Motivate (ate) \\
\hline
\end{tabular}




\begin{tabular}{l|l|l}
\hline Fortunate (ate) & Assistance (ance) & Realize (ize) \\
\hline Definite (ite) & Employee (ee) & Lessen (en) \\
\hline Offensive (ive) & Objective (ive) & \\
\hline Pinkish (ish) & Diversion (ion) & \\
\hline Pakistani (ni) & Motivation (tion) & \\
\hline Global (al) & Implementation (ment+tion) & \\
\hline Psychological (cal) & Leadership (ship) & \\
\hline Stressful (ful) & Manager (er) & \\
\hline Curricular (ar) & Sector (or) & \\
\hline Careless (less) & Business (ness) & \\
\hline Advantageous (ous) & Governments (ment+s) & \\
\hline Important (ant) & Advertisement (ment) & \\
\hline Dependent (ent) & Scientist (ist) & \\
\hline Healthy (th+y) & Legitimacy (acy) & \\
\hline Circulatory (ory) & Factory (y) & \\
\hline & Mentality (ity) & \\
\hline
\end{tabular}

Table 4: Pakistani Written

\begin{tabular}{|c|c|c|}
\hline Adjective & Noun & Verb \\
\hline Scientific (ic) & Childhood (hood) & Facilitate (ate) \\
\hline Recommendable (able) & Service (ice) & Characterize (ize) \\
\hline Sensible (ible) & Attendance (ance) & Dishearten (en) \\
\hline Passionate (ate) & Preference (ence) & \\
\hline Intensive (ive) & Exposure (ure) & \\
\hline Selfish (ish) & Pakistani (I) & \\
\hline Pakistani (i) & Berozgari (i) & \\
\hline Ethical (al) & Chemical (cal) & \\
\hline Geographical (cal) & Material (ial) & \\
\hline Managerial (ial) & Handful (ful) & \\
\hline Medicinal (al) & \begin{tabular}{|l|} 
Boredom (dom) \\
\end{tabular} & \\
\hline Successful (ful) & Enthusiasm (asm) & \\
\hline Western (ern) & Modernism (ism) & \\
\hline Helpless (less) & Guardian (ian) & \\
\hline Religious (ious) & Carcinogen (en) & \\
\hline Ignorant (ant) & \begin{tabular}{|l|} 
Western (ern) \\
\end{tabular} & \\
\hline Consistent (ent) & Campaign (aign) & \\
\hline Smoky (y) & Depression (sion) & \\
\hline Monthly (ly) & Digestion (tion) & \\
\hline \multirow[t]{24}{*}{ Secondary (ary) } & Helpful (ful) & \\
\hline & \begin{tabular}{|l|} 
Relationship (ship) \\
\end{tabular} & \\
\hline & Bystander (er) & \\
\hline & \begin{tabular}{|l|} 
Visitor (or) \\
\end{tabular} & \\
\hline & Academics (ics) & \\
\hline & \begin{tabular}{|l} 
Pakistanis (is) \\
\end{tabular} & \\
\hline & Europeans (eans) & \\
\hline & \begin{tabular}{|l} 
Guardians (ians) \\
\end{tabular} & \\
\hline & Scholarships (ships) & \\
\hline & Advertisers (ers) & \\
\hline & Actors (ors) & \\
\hline & Cleanliness (li+ness) & \\
\hline & Carefulness (ful+ness) & \\
\hline & Dearness (ness) & \\
\hline & Carelessness (less+ness) & \\
\hline & \begin{tabular}{|l} 
Shyness (ness) \\
\end{tabular} & \\
\hline & Treatments (ment $+s)$ & \\
\hline & Addict (ict) & \\
\hline & Dependent (ent) & \\
\hline & Encouragement (ment) & \\
\hline & Dependency (ency) & \\
\hline & Friendly (ly) & \\
\hline & Factory (y) & \\
\hline & Personality (lity) & \\
\hline
\end{tabular}

Table 5: Chinese Spoken

\begin{tabular}{l|l|l}
\hline Adjective & Noun & Verb \\
\hline Academic (ic) & Service (ice) & Broaden (en) \\
\hline Enjoyable (able) & Guidance (ance) & \\
\hline Responsible (ible) & Employee (ee) & \\
\hline Japanese (ese) & Japanese (ese) & \\
\hline Defensive (ive) & Expertise (ise) & \\
\hline English (ish) & English (ish) & \\
\hline Global (al) & Criticism (ism) & \\
\hline Influential (tial) & Discussion (ion) & \\
\hline Meaningful (ful) & Option (tion) & \\
\hline Useless (less) & Scholarship (ship) & \\
\hline
\end{tabular}




\begin{tabular}{l|l|l}
\hline Meaningful (ful) & Engineer (eer) & \\
\hline Poisonous (ous) & Teacher (er) & \\
\hline Pleasant (ant) & Professor (or) & \\
\hline Efficient (ent) & Academics (ics) & \\
\hline Healthy (th+y) & Institutions (ions) & \\
\hline Friendly (ly) & Teachers (ers) & \\
\hline Secondary (ary) & Professors (ors) & \\
\hline Respiratory (ory) & Behaviors (iors) & \\
\hline & Illness (ness) & \\
\hline & Opportuneties (ties) & \\
\hline & Statements (ments) & \\
\hline & Improvement (ment) & \\
\hline & Scientist (ist) & \\
\hline & Chemistry (ry) & \\
\hline & Safety (ty) & \\
\hline
\end{tabular}

Table 6: Chinese Written

\begin{tabular}{|c|c|c|}
\hline Adjectives & Nouns & Verbs \\
\hline Academic (ic) & \begin{tabular}{|l} 
Academic (ic) \\
\end{tabular} & Fasten (en) \\
\hline Enjoyable (able) & Childhood (hood) & \\
\hline Chinese (ese) & \begin{tabular}{|l|} 
Performance (ance) \\
\end{tabular} & \\
\hline Opposite (ite) & Software (ware) & \\
\hline Impressive (ive) & \begin{tabular}{|l} 
Japanese (ese) \\
\end{tabular} & \\
\hline Traditional (al) & \begin{tabular}{|l} 
Detective (ive) \\
\end{tabular} & \\
\hline Thankful (ful) & Criminal (al) & \\
\hline Eastern (ern) & \begin{tabular}{|l|} 
Personnel el) \\
\end{tabular} & \\
\hline Priceless (less) & $\begin{array}{l}\text { Wisdom (dom) } \\
\end{array}$ & \\
\hline Famous (ous) & Impression (sion) & \\
\hline Unimportant (ant) & Lesson (on) & \\
\hline Modernist (ist) & Friendship (ship) & \\
\hline Healthy (th +y) & Officer (er) & \\
\hline Worthy (y) & Economics (ics) & \\
\hline Timely (ly) & Importances (ance $+s)$ & \\
\hline Visionary (ary) & \begin{tabular}{|l} 
Interivewees (ees) \\
\end{tabular} & \\
\hline \multirow[t]{9}{*}{ Guilty (y) } & Possibilities (ity+es) & \\
\hline & $\begin{array}{l}\text { Possessions (ion }+ \text { s) } \\
\text { (ans }\end{array}$ & \\
\hline & Justifications (ation $+\mathrm{s}$ ) & \\
\hline & Leaders $(\mathrm{er}+\mathrm{s})$ & \\
\hline & Awareness (ness) & \\
\hline & Applicants (ant $+s)$ & \\
\hline & Applicators (or+s) & \\
\hline & Developments (ment $+\mathrm{s})$ & \\
\hline & \begin{tabular}{|l} 
Tourists (ist $+\mathrm{s}$ ) \\
\end{tabular} & \\
\hline
\end{tabular}

Table 7: Native Spoken

\begin{tabular}{|c|c|c|}
\hline Adjective & \begin{tabular}{|l|} 
Noun \\
\end{tabular} & Verb \\
\hline Periodic (ic) & Academia (ia) & Patronize (ize) \\
\hline Expandable (able) & \begin{tabular}{|l} 
Difference (ence) \\
\end{tabular} & \\
\hline Irresponsible (ible) & \begin{tabular}{|l|} 
Employee (ee) \\
\end{tabular} & \\
\hline opposite (ite) & \begin{tabular}{|l} 
percentage (age) \\
\end{tabular} & \\
\hline Inclusive (ive) & English (ish) & \\
\hline Selfish (ish) & Criticism (ism) & \\
\hline Ethical (al) & Children (en) & \\
\hline Peaceful (ful) & Impression (ion) & \\
\hline European (an) & Adulthood (hood) & \\
\hline Christian (ian) & \begin{tabular}{|l} 
Japanese (ese) \\
\end{tabular} & \\
\hline Proven (en) & Expenditure (ure) & \\
\hline Western (ern) & Compromise (ise) & \\
\hline Pointless (less) & \begin{tabular}{|l} 
Question (ion) \\
\end{tabular} & \\
\hline Advantageous (ous) & Lesson (on) & \\
\hline Pleasant (ant) & \begin{tabular}{|l|} 
Leadership (ship) \\
\end{tabular} & \\
\hline Independent (ent) & \begin{tabular}{|l|} 
Rubber (er) \\
\end{tabular} & \\
\hline Cloudy (y) & \begin{tabular}{|l|} 
Debator (or) \\
\end{tabular} & \\
\hline Healthy (th+y) & Academics (ics) & \\
\hline Friendly (ly) & Entrances (ance $+\mathrm{s})$ & \\
\hline Rainy (y) & Employees $(\mathrm{ee}+\mathrm{s})$ & \\
\hline \multirow[t]{10}{*}{ Secondary (ary) } & Priorities $(\mathrm{y}=\mathrm{es})$ & \\
\hline & Illnesses (ness+es) & \\
\hline & Personnels (el+s) & \\
\hline & Europeans $($ ean + s) & \\
\hline & \begin{tabular}{|l} 
Citizens $(e n+s)$ \\
\end{tabular} & \\
\hline & Options (ion+s) & \\
\hline & Relationships (tion+ship+s) & \\
\hline & \begin{tabular}{|l} 
Makers (er+s) \\
\end{tabular} & \\
\hline & Goodness (ness) & \\
\hline & Establishments (ment+s) & \\
\hline
\end{tabular}




\begin{tabular}{l|l|l}
\hline & Scientists (ist+s) & \\
\hline & Constituents (ent+s) & \\
\hline & Assistant (ant) & \\
\hline & Employment (ment) & \\
\hline & Activist (ist) & \\
\hline & Activity (ity) & \\
\hline
\end{tabular}

Table 8: Native Written

\begin{tabular}{|c|c|c|}
\hline Adjective & \begin{tabular}{|l} 
Noun \\
\end{tabular} & Verb \\
\hline Economic (ic) & Academia (ia) & Patronise (ise) \\
\hline Applicable (able) & Alcoholic (ic) & Organize (ize) \\
\hline Japanese (ese) & Childhood (hood) & Worsen (en) \\
\hline Fortunate (ate) & Service (ice) & Considerate (ate) \\
\hline Offensive (ive) & Entrance (ance) & \\
\hline Global (al) & Inconvenience (ence) & \\
\hline Chemical (cal) & Wastage (age) & \\
\hline Meaningful (ful) & Japanese (ese) & \\
\hline American (an) & Initiative (ive) & \\
\hline Austrelian (ian) & Grow (th) & \\
\hline Chosen (en) & Removal (al) & \\
\hline Graduation (tion) & Mouthful (ful) & \\
\hline Southern (ern) & Freedom (dom) & \\
\hline Curricular (ar) & Capitalism (ism) & \\
\hline Jobless (less) & Curriculum (lum) & \\
\hline Outrageous (ous) & Citizen (zen) & \\
\hline Reliant (ant) & Heroin (in) & \\
\hline Significant (ant) & Discussion (ion) & \\
\hline Existent (ent) & Institution (tion) & \\
\hline Socialist (ist) & Manifesto (o) & \\
\hline Foggy (y) & Scholarship (ship) & \\
\hline Deadly (ly) & Predator (or) & \\
\hline Primary (ry) & Statistics (ic $+s)$ & \\
\hline Contradictory (ory) & Services (ic+es) & \\
\hline \multirow[t]{25}{*}{ Dirty (y) } & Documentaries $(\mathrm{ry}+\mathrm{s})$ & \\
\hline & References (ence+s) & \\
\hline & Representatives (ent+ive+s) & \\
\hline & Freedoms $(\mathrm{om}+\mathrm{s})$ & \\
\hline & Christians (ian+s) & \\
\hline & Discussions (ion $+\mathrm{s}$ ) & \\
\hline & Organizations (tions $+\mathrm{s}$ ) & \\
\hline & Hardships (ship $+s)$ & \\
\hline & Learners (er+s) & \\
\hline & Professors (or $+\mathrm{s}$ ) & \\
\hline & Effectiveness (ness) & \\
\hline & Addicts (ict $+s$ ) & \\
\hline & Assistants (ant $+\mathrm{s})$ & \\
\hline & Dependents (ent $+s)$ & \\
\hline & Replacements (ment $+\mathrm{s})$ & \\
\hline & Tourists (ist+s) & \\
\hline & Attendant (ent) & \\
\hline & Requirement (ment) & \\
\hline & Consumerist (ist) & \\
\hline & Democracy (acy) & \\
\hline & Frequency (ency) & \\
\hline & Geography (phy) & \\
\hline & Chemistry (ry) & \\
\hline & Nationality (ity) & \\
\hline & Difficulty (y) & \\
\hline
\end{tabular}

These tables given bellow consisting upon the data of spoken forms of three varieties of English represents the morphemes contributing the formation of adjectives. These tables show the frequency-based difference of morphemes and these tables also show the existence and absence of morphemes in the varieties of English on the basis of comparison. This is the detailed and in-depth analysis provides the answer of the $3^{\text {rd }}$ research question. The tables given below provide the morphemes with their frequencies and I provided a comparison of the existence of presence of absence of derivational morphemes in three grammatical categories. This analysis conclusively leads to the difference after comparison with the native data regarding the existence of derivational morphemes.

Table 9: Pakistani spoken adjectives

\begin{tabular}{c|c|c|c|c|c}
\hline Morpheme & Frequency & Morpheme & Frequency & Morpheme & Frequency \\
\hline ic & 268 & i & 14 & ant & 156 \\
\hline able & 44 & al & 425 & ent & 226 \\
\hline ible & 40 & ful & 172 & ment & 2 \\
\hline ate & 36 & ar & 40 & y & 9 \\
\hline ite & 2 & er & 54 & thy & 45 \\
\hline ive & 131 & less & 16 & ly & 16 \\
\hline ish & 6 & ous & 158 & ary & 57 \\
\hline & & & & ory & 14 \\
\hline
\end{tabular}


Adjectives from Pakistani spoken data shows the (i) as morpheme was attached to make adjective from noun further -ar, -er and -ment were found in the data as derivational morpheme which were not found in spoken form of native data. This leads to distinction and creates the difference among varieties.

Table 10: ENS spoken adjectives

\begin{tabular}{c|c|c|c|c|c}
\hline Morpheme & Frequency & Morpheme & Frequency & Morpheme & Frequency \\
\hline ic & 88 & al & 199 & ant & 348 \\
\hline able & 96 & ful & 122 & ent & 101 \\
\hline ible & 24 & an & 7 & y & 87 \\
\hline ese & 5 & ian & 9 & ly & 12 \\
\hline ate & 18 & en & 1 & ary & 64 \\
\hline ite & 1 & ern & 4 & ory & 15 \\
\hline ive & 64 & less & 2 & & \\
\hline ish & 7 & ous & 81 & & \\
\hline
\end{tabular}

This above table shows -ese, -en and -ern were found as derivational morpheme in the adjectives of spoken data of native speakers. All these three morphemes -ese, -en and -ern were not found in the adjectives of spoken data of Pakistan.

Table 11: Chinese spoken adjectives

\begin{tabular}{c|c|c|c|c|c}
\hline Morpheme & Frequency & Morpheme & Frequency & Morpheme & Frequency \\
\hline ic & 42 & ful & 229 & ary & 49 \\
\hline able & 49 & en & 2 & ory & 1 \\
\hline ible & 11 & less & 7 & & \\
\hline ese & 8 & ous & 17 & & \\
\hline ive & 28 & ant & 213 & & \\
\hline ish & 15 & ent & 79 & & \\
\hline th & 1 & y & 42 & & \\
\hline al & 166 & ly & 10 & & \\
\hline
\end{tabular}

Chinese spoken data adjectives as given in the above table show the one morpheme difference which is (th) this derivational morpheme as suffix was not found neither in native variety representing inner circle according to Kachru (1985) nor in expanding circle representing second language speakers of English language.

Table 12: Pakistani spoken noun

\begin{tabular}{c|c|c|c|c|c}
\hline Morpheme & Frequency & Morpheme & Frequency & Morpheme & Frequency \\
\hline hood & 10 & om & 5 & or & 17 \\
\hline ice & 5 & en & 90 & ness & 24 \\
\hline ance & 61 & sion & 34 & ments & 9 \\
\hline ence & 253 & tion & 457 & ent & 391 \\
\hline ee & 4 & on & 4 & ment & 276 \\
\hline ure & 16 & ship & 22 & ist & 1 \\
\hline ive & 3 & er & 186 & acy & 16 \\
\hline ogy & 1 & ity & 160 & & \\
\hline ry & 4 & y & 6 & & \\
\hline
\end{tabular}

Nouns in the Pakistani spoken data showed one morpheme (ogy) which was not found in native data. Overall comparison with native data showed that nouns representing native speakers have variety of derivational morphemes making noun which were absent in Pakistani data.

Table 13: ENS spoken noun

\begin{tabular}{c|c|c|c|c|c}
\hline Morpheme & Frequency & Morpheme & Frequency & Morpheme & Frequency \\
\hline ia & 4 & age & 11 & al & 12 \\
\hline ic & 1 & ure & 5 & el & 1 \\
\hline hood & 4 & ese & 2 & ful & 1 \\
\hline ice & 2 & ise & 6 & om & 32 \\
\hline ance & 31 & ive & 11 & ism & 1 \\
\hline ence & 29 & ish & 1 & en & 82 \\
\hline ee & 1 & th & 218 & sion & 4 \\
\hline tion & 279 & on & 1 & ship & 34 \\
\hline er & 156 & or & 7 & ics & 7 \\
\hline ties & 51 & nesses & 10 & resses & 2 \\
\hline els & 1 & oms & 2 & isms & 2 \\
\hline eans & 1 & ians & 3 & zens & 4 \\
\hline tions & 76 & ons & 6 & ships & 26 \\
\hline ers & 288 & ors & 6 & ness & 34 \\
\hline ments & 30 & ents & 1 & ists & 2 \\
\hline ant & 4 & ment & 257 & ist & 2 \\
\hline ory & 5 & ty & 356 & & \\
\hline
\end{tabular}

Morphemes such as -ia, -ic, -age, -al, -th and -el are the derivational morphemes which are distinctive and were not found in Pakistani data in comparison. Derivational morphemes joining inflectional morpheme to make plurals were also more frequent in native data. Morphemes such as -els, -eans, -nesses, -oms, -ians, -ons, -ents, -ics, -resses, -isms, -zens, -ships and -ists were the morphemes found in native data and absent in spoken data of Pakistani nouns.

Table 14: Chinese Spoken Noun

\begin{tabular}{c|c|c|c|c|c}
\hline Morpheme & Frequency & Morpheme & Frequency & Morpheme & Frequency \\
\hline ice & 3 & on & 5 & ments & 12 \\
\hline
\end{tabular}




\begin{tabular}{c|c|c|c|c|c}
\hline ance & 23 & ship & 17 & ict & 2 \\
\hline ence & 12 & eer & 2 & ent & 4 \\
\hline ee & 2 & er & 118 & ment & 168 \\
\hline ure & 16 & or & 17 & ist & 3 \\
\hline ese & 5 & ics & 8 & ry & 16 \\
\hline ise & 1 & ens & 2 & ty & 5 \\
\hline ense & 8 & tions & 20 & ity & 169 \\
\hline ish & 4 & ships & 5 & & \\
\hline ism & 4 & ers & 198 & & \\
\hline en & 53 & ors & 10 & & \\
\hline sion & 18 & ness & 19 & & \\
\hline tion & 164 & ties & 51 & & \\
\hline
\end{tabular}

Nouns in the Chinese spoken data showed that -eer, -ict and -ense are the distinctive morphemes with comparison to native data.

Table 15: Pakistani spoken verbs

\begin{tabular}{c|c|c|c|c|c}
\hline Morpheme & Frequency & Morpheme & Frequency & Morpheme & Frequency \\
\hline ic & 1 & ate & 2 & ize & 10 \\
\hline en & 6 & & & & \\
\hline
\end{tabular}

Keeping in mind the fact that verbs are mostly formed with the help of inflectional morphemes. Verbs in Pakistani spoken data showed more variation as compared to native data. Pakistani data showed four derivational morphemes serving in the formation of verbs.

Table 16: ENS Spoken verbs

\begin{tabular}{c|c|c|c|c|c}
\hline Morpheme & Frequency & Morpheme & Frequency & Morpheme & Frequency \\
\hline Ize & 12 & & & & \\
\hline
\end{tabular}

Native data showed only one derivational morpheme -ize which was also found in Pakistani data but at different frequency.

Table 17: Chinese spoken verb

\begin{tabular}{c|c|c|c|c|c}
\hline Morpheme & Frequency & Morpheme & Frequency & Morpheme & Frequency \\
\hline En & 4 & & & & \\
\hline
\end{tabular}

The only one morpheme -en found in the verbs of Chinese spoken data and it showed the deviation from native data this morpheme was not found in verbs of native spoken data.

Table 18: Pakistani written adjectives

\begin{tabular}{c|c|c|c|c|c}
\hline Morpheme & Frequency & Morpheme & Frequency & Morpheme & Frequency \\
\hline Ic & 135 & al & 379 & en & 1 \\
\hline able & 83 & ful & 199 & less & 25 \\
\hline ible & 50 & ean & 9 & ous & 265 \\
\hline ate & 5 & an & 6 & ant & 123 \\
\hline ive & 102 & tion & 1 & ent & 175 \\
\hline ish & 8 & ern & 14 & y & 80 \\
\hline i & 5 & ar & 11 & ly & 66 \\
\hline ary & 129 & ory & 31 & & \\
\hline
\end{tabular}

Adjectives in the written data of Pakistan showed deviation from native data. Derivational morphemes (such as -ean, -an, -ish, and -i) were found distinctive from native data.

Table 19: ENS written adjectives

\begin{tabular}{c|c|c|c|c|c}
\hline Morpheme & Frequency & Morpheme & Frequency & Morpheme & Frequency \\
\hline ic & 119 & ian & 10 & ment & 1 \\
\hline able & 165 & en & 14 & est & 1 \\
\hline ible & 63 & tion & 1 & ist & 5 \\
\hline ese & 89 & ern & 2 & thy & 37 \\
\hline ate & 16 & ar & 15 & y & 55 \\
\hline ite & 4 & less & 19 & ly & 43 \\
\hline ive & 132 & ous & 65 & ary & 65 \\
\hline al & 317 & ant & 238 & ery & 1 \\
\hline ful & 99 & ent & 86 & ory & 22 \\
\hline
\end{tabular}

Adjectives in the written native data showed that derivational morphemes such as -ment, -ese, -est, -ist, -thy and -ery are the distinctive morphemes. While comparison with ESL variety these morphemes were found missing in the data of Pakistani written corpus.

Table 20: Chinese written adjectives

\begin{tabular}{c|c|c|c|c|c}
\hline Morpheme & Frequency & Morpheme & Frequency & Morpheme & Frequency \\
\hline Ic & 68 & ate & 10 & ern & 2 \\
\hline Able & 122 & ite & 9 & ar & 10 \\
\hline ible & 46 & ive & 51 & less & 17 \\
\hline Le & 12 & al & 394 & ous & 23 \\
\hline Ese & 13 & ful & 195 & ant & 603 \\
\hline Thy & 4 & ist & 1 & ent & 283 \\
\hline Ly & 13 & y & 10 & ary & 139 \\
\hline
\end{tabular}


Adjectives in the written data of Chinese corpus showed slight deviation from native data. Morphemes such as -lte, -le, and -ese were the morphemes different from native and second language data.

Table 21: Pakistani written noun

\begin{tabular}{c|c|c|c|c|c}
\hline Morpheme & Frequency & Morpheme & Frequency & Morpheme & Frequency \\
\hline Ic & 1 & sion & 92 & iors & 2 \\
\hline hood & 3 & tion & 705 & ors & 18 \\
\hline ice & 3 & ful & 2 & ness & 111 \\
\hline ance & 47 & ship & 12 & ments & 46 \\
\hline ence & 96 & er & 238 & ent & 5 \\
\hline age & 28 & ior & 1 & ict & 35 \\
\hline cle & 1 & or & 13 & ant & 1 \\
\hline ine & 91 & ics & 7 & ment & 419 \\
\hline ure & 40 & ances & 11 & acy & 19 \\
\hline th & 351 & ees & 7 & ogy & 5 \\
\hline i & 2 & ures & 21 & ly & 2 \\
\hline ful & 7 & is & 1 & ary & 2 \\
\hline dom & 6 & als & 3 & ery & 1 \\
\hline ism & 4 & ans & 4 & ory & 2 \\
\hline ian & 3 & ians & 4 & ry & 4 \\
\hline ern & 1 & ions & 93 & ity & 242 \\
\hline en & 8 & ships & 16 & ty & 10 \\
\hline ign & 1 & ers & 12 & & \\
\hline
\end{tabular}

Nouns in the written data of Pakistani variety representing second language learners of English showed that -iors, -ors, -ior, -ees, -ances, cle, -ine, -i, -ian, -ern and -ign were the distinctive morphemes. Data showed that Pakistani writers have less tendency to add plurals with the derivational morphemes while making nouns.

Table 22: ENS written noun

\begin{tabular}{c|c|c|c|c|c}
\hline Morpheme & Frequency & Morpheme & Frequency & Morpheme & Frequency \\
\hline Ia & 4 & ism & 5 & ties & 85 \\
\hline A & 2 & um & 3 & ences & 4 \\
\hline Ic & 1 & en & 3 & nesses & 4 \\
\hline hood & 4 & in & 1 & resses & 1 \\
\hline Ice & 10 & sion & 35 & ives & 6 \\
\hline ance & 54 & tion & 440 & als & 1 \\
\hline ence & 38 & on & 9 & oms & 4 \\
\hline ee & 5 & ship & 21 & ians & 7 \\
\hline age & 10 & er & 134 & ens & 26 \\
\hline ure & 42 & or & 20 & sions & 21 \\
\hline ese & 8 & eur & 1 & tions & 134 \\
\hline ive & 25 & our & 4 & ons & 7 \\
\hline th & 153 & ics & 12 & ers & 569 \\
\hline al & 7 & ices & 2 & eurs & 7 \\
\hline el & 2 & ances & 12 & ness & 111 \\
\hline ful & 2 & ages & 5 & ress & 2 \\
\hline dom & 40 & aches & 1 & icts & 3 \\
\hline ants & 6 & ents & 627 & ments & 125 \\
\hline ents & 2 & aints & 2 & ists & 6 \\
\hline ant & 12 & ent & 192 & ment & 295 \\
\hline ist & 2 & acy & 8 & cy & 6 \\
\hline gy & 15 & y & 9 & ry & 2 \\
\hline ty & 40 & ity & 231 & & \\
\hline & & & & & \\
\hline
\end{tabular}

Nouns in the written native data showed number of distinctive derivational morphemes. Native data showed higher number of derivational morphemes as compared to outer and expanding circle varieties. Morphemes such as -ia, -a, -um, -age, -ese, -el, and -gy, are the distinctive morphemes with comparison to ESL variety. Tendency to make plurals by adding -s as inflection with derivational morpheme is much higher in native variety than other varieties of English. Morphemes such as ages, -aints, -ists, -icts, -ress, -eurs, -ons, -tions, -sions, -ens, ians, -ives, -ences, -nesses, -resses are the morphemes which are found in native data and these are the distinctive morphemes.

Table 23: Chinese written noun

\begin{tabular}{c|c|c|c|c|c}
\hline Morpheme & Frequency & Morpheme & Frequency & Morpheme & Frequency \\
\hline ic & 4 & on & 71 & ors & 24 \\
\hline hood & 3 & ship & 65 & ness & 129 \\
\hline ance & 223 & er & 405 & ants & 1 \\
\hline ee & 13 & ior & 62 & ments & 82 \\
\hline ware & 5 & or & 15 & ents & 5 \\
\hline aire & 1 & ics & 15 & ists & 22 \\
\hline ure & 133 & ices & 2 & & \\
\hline ese & 4 & ances & 10 & & \\
\hline ive & 39 & ences & 4 & & \\
\hline ish & 11 & ties & 198 & & \\
\hline al & 21 & nesses & 7 & & \\
\hline el & 1 & resses & 3 & & \\
\hline dom & 37 & als & 2 & & \\
\hline ean & 1 & ians & 3 & & \\
\hline ian & 3 & ions & 13 & & \\
\hline
\end{tabular}




\begin{tabular}{c|c|c|c|l|l}
\hline en & 6 & tions & 133 & & \\
\hline ion & 5 & ships & 11 & & \\
\hline sion & 161 & ers & 1033 & & \\
\hline tion & 823 & iors & 9 & & \\
\hline
\end{tabular}

Nouns in the written data of Chinese corpus showed slight deviation from native data. In result of comparison with the native data showed that nouns in the Chinese data showed that morphemes such as -ware, -aire, -ish and -i are the morphemes which were not found in the native data for making nouns.

Table 24: Paki written verb

\begin{tabular}{c|c|c|c|c|c}
\hline Morpheme & Frequency & Morpheme & Frequency & Morpheme & Frequency \\
\hline Ate & 2 & ize & 2 & en & 1 \\
\hline
\end{tabular}

The abovementioned table shows all the morphemes which were found in the written data of Pakistani corpus form making verbs. Data showed that all patterns were similar to native data and all these patterns were existent in native corpus.

Table 25: ENS written verb

\begin{tabular}{c|c|c|c|c|c}
\hline Morpheme & Frequency & Morpheme & Frequency & Morpheme & Frequency \\
\hline ise & 1 & ize & 16 & en & 4 \\
\hline Ate & 3 & & & & \\
\hline
\end{tabular}

Written data of native corpus showed slight deviation. Results and comparison with SL and FL variety showed that -ise is the only morpheme which is not found in other two varieties.

Table 26: Chinese written verb

\begin{tabular}{c|c|c|c|c|c}
\hline Morpheme & Frequency & Morpheme & Frequency & Morpheme & Frequency \\
\hline En & 11 & & & & \\
\hline
\end{tabular}

Written data of Chinese verbs showed that -en is the only morpheme found in the FL variety. Other morphemes found in native and SL variety were not found in FL variety. It can be concluded from this that native and second language writers are more proficient than FL learners.

\section{Discussion}

As we are aware that morphemes play vital role in forming words. While analyzing data it appeared that with addition to derivational morphemes attached to the root to make words it was also seen that inflectional morphemes are also linked in addition to the derivational morphemes to make words. Examples of this pattern are developments (ment+s) and hardships (ship $+\mathrm{s})$.

The other mentionable pattern observed while analysis is that few roots carry two derivational morphemes at the position of suffix to form words. The words like carelessness (less+ness) and carefulness (ful+ness) are the examples of this idea.

The most interesting discovery of this study is that data analysis of Pakistani data showed distinct pattern. As it is an obvious notion Local language plays vital role while making words of the language of the colonizer. The data from the ICNALE, a Pakistani portion, showed the word "Pakistani" which is formed by combining the root "Pakistan" and derivational morpheme (i).

Many words in our local languages such as Urdu and Punjabi appear to be forming the words at this pattern by adding the morpheme (i) with the base word to form the words which can be noun or adjectives. The example of this pattern from our local languages are Punjabi, Sindhi and so on. From these examples it can be hypothesized that only national or ethical nouns, or adjectives are made at such pattern but Pakistani data showed another example which was "Berozgari". In this word, the same pattern appears of adding the morpheme (i) with the root word.

Other national nouns and adjectives appeared on the pattern of Asian (-an), European (-an), English (-ish), and Australian (-an). These patterns and the derivational morphemes belong to English language, and are derived from English, but the pattern appeared in Pakistani data is its distinctive pattern which is influenced by local languages of Pakistan.

\section{Conclusion}

On the basis of data analysis, the results showed that differences are observed in the form of occurrences of derivational morphemes across all three (native, second and foreign) English language varieties. The native data showed higher and more frequent occurrence of derivational morphemes as compared to other two varieties. The results showed that the tendency to make plurals is much higher in native variety. So, the data shows that native language learners are more proficient than second and foreign language learners. Further, these derivational morphemes can be helpful in language learning. These morphemes can be taught to learners and by mentioning the derivational morphemes of different categories can help learners in English language learning and understanding. The patterns of native variety should also be taught to leaners to make them more proficient and to create native like proficiency in the second and foreign language learners.

\section{Implications of the study}

In result of the comparative analysis conducted in the study, the distinctive morphemic patterns were found across three varieties and native learners found more competitive in the use of derivational morphemes. So, those morphemes reported in the study should also be taught to second and foreign language learners of English language to achieve native like command in English language.

\section{References}

Bauer, L. (1988). Introducing linguistic morphology (Vol. 57). Edinburgh: Edinburgh University Press.

Boey, L. K. (1975). An introduction to linguistics for the language teacher. Singapore University Press for Regional English Language Centre.

Cook, H. M. (2008). Socializing identities through speech style: Learners of Japanese as a foreign language. Multilingual Matters.

Demirela, E. T., \& Kazazoğlub, S. (2015). The comparison of collocation use by Turkish and Asian learners of English: the case of TCSE corpus and ICNALE corpus. Procedia - Social and Behavioral Sciences, 174, 2278-2284. 
Dost, I. N., \& Bohloulzadeh, G. (2017). A Review of Contrastive Analysis Hypothesis with a Phonological and Syntactical View: A Cross Linguistic Study. The Buckingham Journal of language and linguistics, 10, 32-41.

Edwards, E. C. (2003). Vocabulary tricks: Effects of instruction in morphology and context on fifth-grade students' ability to derive and infer word meanings. American educational research journal, 40(2), 447-494.

Haspelmath, M., \& Sims, A. D. (2013). Understanding Morphology. Oxon: Routledge.

Ishikawa, S. (2011). A new horizon in learner corpus studies: the aim of the ICNALE project. Corpora and language technologies in teaching, learning and Research, 3-11.

Ishikawa, S. I. (2013). The ICNALE and sophisticated contrastive interlanguage analysis of Asian learners of English. Learner corpus studies in Asia and the world, 1(1), 91-118.

Ishikawa, S. I. (2019). The ICNALE Spoken Dialogue: A new dataset for the study of Asian learners' performance in L2 English interviews. English Teaching, 74(4), 153-177.

Jassem, Z. A. (2013). The English, German, and French cognates of Arabic back consonants: A lexical root theory approach. International Journal of English and Education 2 (2), 108-128.

Kachru, B. B. (1981). "Socially realistic linguistics": the Firthian tradition. International Journal of the Sociology of Language, 1981(31), $65-90$.

Kachru, B. B. (1985). The bilinguals' creativity. Annual Review of Applied Linguistics, 6, 20-33.

McCarthy, M., \& O'Keeffe, A. (2010). What are corpora and how have they evolved? In A. O"Keeffe, \& M. McCarthy, The Routledge Handbook of Corpus Linguistics (pp. 3-13). Routledge.

Wardhaugh, R. (1970). The Contrastive Analysis Hypothesis. TESOL Quarterly, 18-21

Yule, G. (2016). The study of language. Cambridge University Press. 